\title{
Co-Cultivation of Human Aortic Smooth Muscle Cells With Epicardial Adipocytes Affects Their Proliferation Rate
}

\author{
J. ŽDYCHOVÁ ${ }^{1}$, S. ČEJKOVÁ ${ }^{1}$, I. KRÁLOVÁ LESNÁ ${ }^{1}$, A. KRÁLOVÁ ${ }^{1}$, \\ J. MALUŠKOVÁ ${ }^{2}$, L. JANOUŠEK ${ }^{3}$, L. KAZDOVÁ ${ }^{1}$
}

${ }^{1}$ Center for Experimental Medicine, Institute for Clinical and Experimental Medicine, Prague, Czech Republic, ${ }^{2}$ Department of Pathology, Institute for Clinical and Experimental Medicine, Prague, Czech Republic, ${ }^{3}$ Department of Transplant Surgery, Institute for Clinical and Experimental Medicine, Prague, Czech Republic

Received August 4, 2014

Accepted August 15, 2014

\section{Summary}

The abnormal proliferation of vascular smooth muscle cells (VSMC) is thought to play a role in the pathogenesis of atherosclerosis. Adipocytes produce several bioactive paracrine substances that can affect the growth and migration of VSMCs. Our study focuses on the direct effect of the bioactive substances in conditioned media (CM) that was obtained by incubation with primary adipocyte-derived cell lines, including cell lines derived from both preadipocytes and from more mature cells, on the proliferation rate of human aortic smooth muscle cells (HAoSMCs). We used a Luminex assay to measure the adipokine content of the $\mathrm{CM}$ and showed that there was a higher concentration of monocyte chemoattractant protein-1 in renal preadipocyte-CM compared with the HAoSMC control $(p<0.5)$. The addition of both renal preadipocyte- and epicardial adipocyte- CM resulted in the elevated production of vascular endothelial growth factor compared with the control HASOSMC CM $(p<0.001)$. The adiponectin content in renal adipocyte-CM was increased compared to all the remaining adipocyte-CM $(p<0.01)$. Moreover, the results showed a higher proliferation rate of HAoSMCs after co-culture with epicardial adipocyte-CM compared to the HAoSMC control $(p<0.05)$. These results suggest that bioactive substances produced by adipocytes have a stimulatory effect on the proliferation of VSMCs.

\section{Key words}

Atherosclerosis • Proliferation • Inflammation • Adipokines

\section{Corresponding author}

J. Ždychová, Department of Metabolism and Diabetes, Center for Experimental Medicine, Institute for Clinical and Experimental Medicine, Vídeňská 1958/9, Prague 14021, Czech Republic. E-mail: jana.zdychova@ikem.cz

\section{Introduction}

Obesity, the most common nutritional disorder in industrialized countries, is associated with the accelerated progression of atherosclerosis and its clinical complications (Calle et al. 1999). Currently, adipose tissue is perceived not only as a reservoir of energy but also as an important endocrine and immunologically active tissue that produces various bioactive substances, particularly, adipokines. It is well-established that various levels of adipokines are produced in the adipose tissue of lean vs obese individuals. Adipose tissue of obese individuals shows signs of low-grade inflammation together with infiltration of adipose tissue macrophages. Moreover, obese individuals have higher circulating concentrations of many inflammatory markers compared with lean people. The source of these mediators within the adipose tissue is not clear, but infiltrating macrophages seem to be especially important. However, adipocytes themselves also play a significant role (Calder et al. 2011). Adipose tissue can be divided into two basic groups: visceral and subcutaneous adipose tissue. Virtually all blood vessels are surrounded by various amounts of a special type of visceral adipose tissue (Cinti 
2002). For a long time, perivascular adipose tissue (PVAT) was considered to be a rather passive structural support for vessels, but the vasocrine function of PVAT has been extensively studied (Gao 2007). Perivascular adipocytes are similar to adipocytes of visceral adipose tissue, which is a well-known producer of various bioactive substances with apocrine, paracrine and endocrine effects. They appear to be powerful endocrine cells capable of responding to metabolite cues (Chartterjee et al. 2009) and are capable of signal transduction to adjacent blood vessels through a paracrine or vasocrine signaling pathway (Gustafson 2010). This "outside-to-inside signaling paradigm" suggests that biologically active mediators produced by PVAT may have a pathologic role in the development of atherosclerosis (Mazurek et al. 2003, Yudkin et al. 2005). Epicardial adipose tissue (EAT) is a type of perivascular fat, located in the chest near the adventitia of the coronary arteries. Some evidence demonstrates a relationship between epicardial and visceral fat masses (Iacobellis et al. 2003). The expansion of visceral adipose tissue is associated with a high risk of metabolic syndrome and incidence of cardiovascular disease (Despres et al. 2008, Piche et al. 2008). Clinical findings, together with ex vivo and in vitro studies, suggest that EAT plays an important role in the process of the pathogenesis of atherosclerosis (Taguchi et al. 2001, Mazurek et al. 2003, Ding et al. 2008, Chartterjee et al. 2009, Zhou et al. 2011).

The abnormal proliferation of vascular smooth muscle cells (VSMCs) is thought to play an important role in the pathogenesis of atherosclerosis and in-stent restenosis via the mechanism of neo-intimal formation. The migration of VSMCs from the media to the intima, together with phenotypic modulation, is defined as a switch from a contractile phenotype (in which cells have increased cytoplasmic myofilaments and are involved in the maintenance of vascular tone) to a synthetic phenotype (where cells, although less contractible, upregulate the machinery required for proliferation, migration, and production of the extracellular matrix); this migration also reduces the expression of contractile genes compared to cells with a contractile phenotype (Owens et al. 2004). VSMCs can switch between these states, but the regulation of this balance is disrupted in proliferative and obstructive vascular diseases such as atherosclerosis, restenosis after angioplasty, and pulmonary hypertension (DavisDusenbery et al. 2011). Several studies indicate that growth factor/cytokine-signaling can dramatically affect the phenotypic status of VSMCs. For example, interleukin 6 (IL-6) (Ikeda et al. 1991), interleukin 8 (IL-8) (Yue et al. 1994), interleukin 1 alpha (IL-1 alpha) (Schultz et al. 2007), vascular endothelial growth factor (VEGF) (Schlich et al. 2013), monocyte chemoattractant protein-1 (MCP-1) and platelet-derived growth factor (PDGF) (Miao and Li 2012) can promote DNA synthesis in VSMCs and cause cell proliferation.

Adipocytes produce several paracrine bioactive substances that can affect the growth and migration of VSMCs and which can eventually contribute to the development of proliferative vascular disease (Kiefer et al. 2012, Szasz et al. 2013). A study by Barandier et al. (2005) identified protein as one of the responsible factors, as both boiling and digestion with proteinase $\mathrm{K}$ decrease the pro-proliferative effect of conditioned media on the growth of VSMCs. The remaining effect of treated conditioned media on the proliferation of VSMCs could be ascribed to nonprotein factors. For example, free fatty acids (primarily oleic acid), are also able to induce the proliferation of VSMCs (Lamers et al. 2011). However, the network of mechanisms and factors responsible for aberrant VSMC proliferation is far from understood. Although the effects of several individual adipokines on VSMC function have been previously reported (Szasz et al. 2013), the effects of the complex secretory output of human adipocytes has not been fully investigated. Our study was designed to compare the effect of bioactive substances produced by epicardial and renal preadipocytes and adipocyte primary cell lines on the proliferation rate of human aortic smooth muscle cells (HAoSMCs). Based on the foundations set forth in previous studies, we focused on the following adipokines: IL-6, IL-8, MCP-1, VEGF and adiponectin. A study by Schlich et al. (2013) found VEGF levels in conditioned medium (CM) to be significantly correlated with the proliferation rate of VSMCs. Moreover, their study showed that VEGF is most likely not the only important factor for VSMC proliferation. As CM contains various adipokines such as IL-6, IL-8 and MCP-1 (DietzeSchroeder et al. 2005), it is possible that some of these adipokines, in addition to VEGF, induce VSMC proliferation. Adiponectin also seems to be an important factor. A study by Lamers et al. (2011) presumed that the adiponectin content in $\mathrm{CM}$ might be responsible for the differences in the proliferative potency of CM. 


\section{Materials and Methods}

\section{Cell culture}

The following experiments were approved by the Ethical Committee of the Institute for Clinical and Experimental Medicine. All donors signed an informed consent. Renal adipose tissue was selected to represent visceral fat. Samples of renal and subcutaneous adipose tissues were collected exclusively from healthy volunteers during kinship organ transplantations. The EAT samples were obtained from the explanted hearts of patients who received a transplant because of cardiomyopathy. The EAT samples were taken from the following locations: the right side of the coronary artery, the ramus circumflexus and the anterior descending branch of the coronary artery. All fat samples used in our study were obtained from middle aged men. In order to minimize the influence of pre-existing pathologies, only patients who experienced no clinical signs of atherosclerosis and had no evidence of diabetes according to routine laboratory tests were selected for the study. Paired biopsies from subcutaneous and renal adipose tissues were obtained from two sample donors (the first donor was 38 years old, body mass index $27.5 \mathrm{~kg} / \mathrm{m}^{2}$; the second donor was 35 years old, body mass index $29.19 \mathrm{~kg} / \mathrm{m}^{2}$ ). Samples of EAT were obtained also from two donors (the first donor was 51 years old, body mass index $31.1 \mathrm{~kg} / \mathrm{m}^{2}$; the second donor was 54 years old, body mass index $30.1 \mathrm{~kg} / \mathrm{m}^{2}$ ). Donors did not receive long-term treatment with medication that could, according to our knowledge, affect the outcome of the study. The preparation of the adipose tissue cultures was performed as previously described (Fried and MoustaidMoussa 2001). Briefly, only the EAT adipose tissue samples were subsequently pooled and, similar to the renal and subcutaneous samples, were minced with scissors into small pieces $\left(2-4 \mathrm{~mm}^{3}\right)$ under aseptic conditions. The minced tissue samples were washed in PBS, placed in digestion solution $(2 \mathrm{mg} / \mathrm{ml}$ collagenase, $2 \%$ fatty acid-free BSA in PBS) and incubated in a shaker $(200 \mathrm{rpm})$ at $37^{\circ} \mathrm{C}$ for $1 \mathrm{~h}$. The collagenasedigested samples were separated from undigested tissue by filtration through a $200-\mu \mathrm{m}$ mesh fabric. Floating fat cells were separated from the stromal vascular fraction (SVF) by centrifugation at $200 \mathrm{~g} \times 10 \mathrm{~min}$. The SVF that contained the preadipocytes was subsequently washed several times and was finally resuspended in a selective preadipocyte growth medium (Promo Cell, Heidelberg, Germany), cultivated in a culture flask and maintained in an incubator at $37^{\circ} \mathrm{C}$ and $5 \%(\mathrm{v} / \mathrm{v}) \mathrm{CO}_{2}$. The medium was changed every 2-3 days unless otherwise stated. At subconfluent densities, the cultured cells were trypsinized and plated in triplicate for each condition into 12-well plates at $0.1 \times 10^{6}$ cells/well. When the cell monolayer cultures reached $\sim 90 \%$ confluence, the cells were induced to differentiate. The cells were subsequently cultured for a total of 21 days in order to obtain mature adipocytes. The cells were cultured in an adipocyte differentiation medium for the first 3 days and were later cultured in an adipocyte nutrition medium (Promo Cell, Heidelberg, Germany). The degree of adipocyte differentiation was determined by oil-red staining (Sigma Aldrich, St. Louis, MO, USA). The conditioned medium was prepared as follows: subconfluent preadipocytes or adipocytes were washed and kept in a preadipocyte growth medium or adipocyte nutrition medium for $24 \mathrm{~h}$. The conditioned medium was collected, centrifuged (13000 rpm for $10 \mathrm{~min}$ at $4{ }^{\circ} \mathrm{C}$ ) to remove cell debris, frozen and kept at $-80{ }^{\circ} \mathrm{C}$ until further use. All experiments were performed on cells at passage 6 or less, and each condition was assayed in triplicate in two independent experiments.

\section{Cell proliferation assay}

We used the Real-Time cell analyzer xCELLigence System, together with E-Plate View 16 (Roche Applied Science, Basel, Switzerland) to measure the level of cell proliferation in primary cell cultures of HAoSMCs during co-cultivation with conditioned media. The conditioned medium was obtained from primary cell cultures of both undifferentiated and mature adipocytes. HAoSMCs were seeded at an initial density of $2 \times 10^{3}$ cells per well and allowed to attach. The cells were washed and rendered quiescent for $24 \mathrm{~h}$ in a serum-free HAoSMC growth medium. Conditioned media obtained from adipocyte cell lines were added in the amount of $37.5 \% \mathrm{v} / \mathrm{v}$ in Smooth Muscle Cell Growth Medium 2 (Promo Cell, Heidelberg, Germany). All experiments were performed on cells at passage 6 or less, and each condition was assayed in triplicate in two independent experiments.

\section{Luminex assay}

The Luminex assay is a multiplex bead-based immunoassay, which allows for the simultaneous measurement of multiple analytes (e.g. adipokines) using a library of antibody-coupled color-coded beads. Human cytokine Luminex kits for IL-6, IL-8, MCP-1, VEGF and 
adiponectin were purchased from R\&D (R\&D Systems Inc, Minneapolis, MN, USA). The assay was performed in 96-well plates, and all reagents and plates were prepared according to the manufacturers' instructions. We measured the cytokines present in the conditioned media that had been incubated with adipocyte cell lines for $24 \mathrm{~h}$. Each condition was assayed in triplicate in two independent experiments. Plates were read by the Luminex 100 analyzer (PerkinElmer, Inc, MA, USA) using XPONENT software (Luminex, Austin, TX, USA). The triplicate readings for each standard, quality control and sample were averaged, and the average Median Fluorescence Intensity (MFI) of the blank was subtracted. An acquisition gate of between 7500 and 15500 was set to discriminate against any doubled events and ensure that only single microbeads were measured. A total of $100 \mathrm{beads} /$ well was collected, and MFI readings were measured. The MFI readings were converted to concentrations using the best parameter logistic fit curve, which was generated for each analyte from the seven standards using Multiplex Analyst software (Millipore).

\section{Statistical analysis}

The data are always presented as a mean \pm standard deviation (SD). The statistical analysis was performed using Student's t-test or ANOVA (post-hoc test: Bonferroni's multiple comparison test). Differences were considered statistically significant at the level of $\mathrm{p}<0.05$.

\section{Results}

Adipokine production in conditioned media from undifferentiated and mature human adipocyte cell lines

The production of adipokines (IL-6, IL-8, MCP-1, VEGF and adiponectin) from epicardial, renal and subcutaneous pre- and fully differentiated adipocytes in conditioned media (CM) was measured by a Luminex assay. The adipokine content in $\mathrm{CM}$ of the primary cell line of HAoSMCs was considered as a reference standard (100\%) (Fig. 1A and 1B are associated with the p-value data displayed in Table 1). Our results showed varying levels of adipokine production that was dependent on the cell origin and the differentiation status of the cell line. No IL-6, IL-8, MCP-1 or VEGF was detected in pure preadipocyte growth, adipocyte nutrition or Smooth Muscle Cell Growth Medium 2 media. Our results showed that HAoSMCs produced significantly higher amounts of IL-6, IL-8, MCP-1 and VEGF compared to adipocyte cell lines, derived from both undifferentiated and differentiated cells (for all groups, $\mathrm{p}<0.01$ ). Only renal preadipocyte-CM showed an increased production of MCP-1 compared to the HAoSMC control $(\mathrm{p}<0.05)$. Renal preadipocyte-CM and epicardial adipocyte-CM also demonstrated a higher production of VEGF compared to the control $(\mathrm{p}<0.001)$. The amount of IL8 in epicardial preadipocyte-CM and subcutaneous preadipocyte-CM was similar to the control.
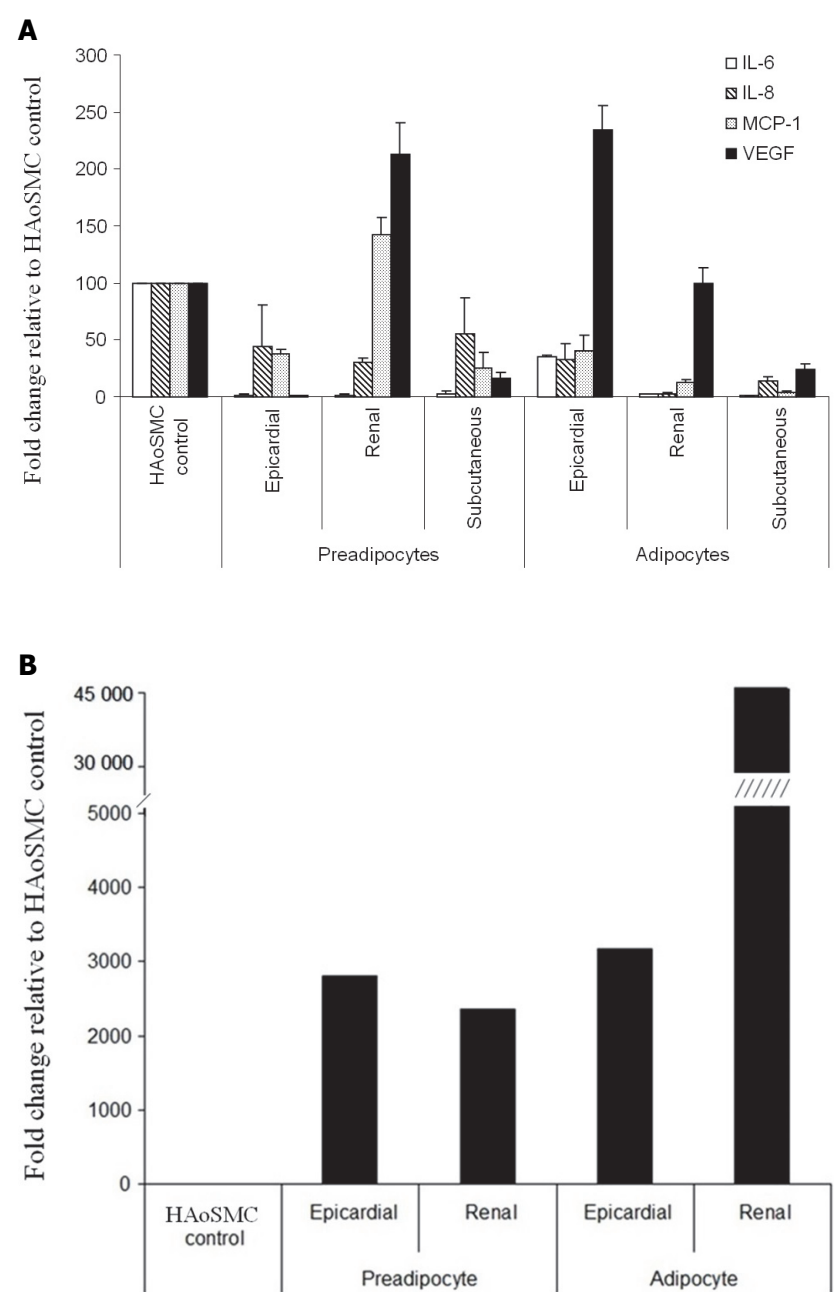

Fig. 1. Relative content of adipokine production (IL-6, IL-8, MCP-1, VEGF and adiponectin) in conditioned media. Conditioned media were obtained during a 24-h incubation with control primary cell line derived from HAoSMCs and with both undifferentiated and mature adipocyte cell lines. The adipokine content in the conditioned medium of the HAoSMCs was considered a reference standard (100\% or 1.0). Relative content of IL-6, IL-8, MCP-1, and VEGF in conditioned media (A). Relative content of adiponectin in conditioned media (B). All experiments were performed in triplicate for each condition, and the results are presented as the mean \pm SD for two independent experiments. Figure $1 \mathrm{~A}$ and $1 \mathrm{~B}$ are associated with the $\mathrm{p}$-value data displayed in Table 1 . Values were considered to be significantly different at $\mathrm{p}<0.05$. 
Table 1. The level of significance of the adipokine content (IL-6, IL-8, MCP-1, VEGF and adiponectin) associated Figure 1A and 1B.

\begin{tabular}{|c|c|c|c|c|c|c|c|}
\hline & & $\begin{array}{c}\text { Epicardial } \\
\text { preadipocyte } \\
\text { CM }\end{array}$ & $\begin{array}{c}\text { Renal } \\
\text { preadipocyte } \\
\text { CM }\end{array}$ & $\begin{array}{c}\text { Subcutaneous } \\
\text { preadipocyte } \\
\text { CM }\end{array}$ & $\begin{array}{c}\text { Epicardial } \\
\text { adipocyte } \\
\text { CM }\end{array}$ & $\begin{array}{c}\text { Renal } \\
\text { adipocyte } \\
\text { CM }\end{array}$ & $\begin{array}{c}\text { Subcutaneous } \\
\text { adipocyte } \\
\text { CM }\end{array}$ \\
\hline$I L-6$ & $\begin{array}{l}\text { vs } H A o S M C \\
C M\end{array}$ & $* * * \downarrow$ & $* * * \downarrow$ & $* * * \downarrow$ & $* * * \downarrow$ & $* * * \downarrow$ & $* * * \downarrow$ \\
\hline$I L-8$ & $\begin{array}{l}\text { vs } H A o S M C \\
C M\end{array}$ & n.s. & $* * * \downarrow$ & n.s. & $* * \downarrow$ & $* * * \downarrow$ & $* * * \downarrow$ \\
\hline$M C P-1$ & $\begin{array}{l}\text { vs } H A o S M C \\
C M\end{array}$ & $* * * \downarrow$ & $* \uparrow$ & $* * * \downarrow$ & $* * \downarrow$ & $* * * \downarrow$ & $* * * \downarrow$ \\
\hline$V E G F$ & $\begin{array}{l}\text { vs } H A o S M C \\
C M\end{array}$ & $* * * \downarrow$ & $* * * \uparrow$ & $* * * \downarrow$ & $* * * \uparrow$ & n.s. & $* * * \downarrow$ \\
\hline Adiponectin & $\begin{array}{l}\text { vs } H A o S M C \\
C M\end{array}$ & $* * \uparrow$ & n.s. & n.a. & n.s. & $* * * \uparrow$ & n.a. \\
\hline$I L-6$ & $\begin{array}{l}\text { vs Epicardial } \\
\text { adipocyte } C M\end{array}$ & $* * * \downarrow$ & $* * * \downarrow$ & $* * * \downarrow$ & $\mathrm{p}=1$ & $* * * \downarrow$ & $* * * \downarrow$ \\
\hline$I L-8$ & $\begin{array}{l}\text { vs Epicardial } \\
\text { adipocyte CM }\end{array}$ & n.s. & n.s. & n.s. & $\mathrm{p}=1$ & $* \downarrow$ & n.s. \\
\hline$M C P-1$ & $\begin{array}{l}\text { vs Epicardial } \\
\text { adipocyte } C M\end{array}$ & n.s. & $* * * \uparrow$ & n.s. & $\mathrm{p}=1$ & $* \downarrow$ & $* * \downarrow$ \\
\hline$V E G F$ & $\begin{array}{l}\text { vs Epicardial } \\
\text { adipocyte CM }\end{array}$ & $* * * \downarrow$ & n.s. & $* * * \downarrow$ & $\mathrm{p}=1$ & $* * * \downarrow$ & $* * * \downarrow$ \\
\hline Adiponectin & $\begin{array}{l}\text { vs Epicardial } \\
\text { adipocyte } C M\end{array}$ & n.s. & n.s. & n.a. & $\mathrm{p}=1$ & $* * \uparrow$ & n.a. \\
\hline$I L-6$ & $\begin{array}{l}\text { vs Renal } \\
\text { adipocyte CM }\end{array}$ & n.s. & n.s. & n.s. & $* * * \uparrow$ & $\mathrm{p}=1$ & n.s. \\
\hline$I L-8$ & $\begin{array}{l}\text { vs Renal } \\
\text { adipocyte CM }\end{array}$ & n.s. & $* * * \uparrow$ & n.s. & $* \uparrow$ & $\mathrm{p}=1$ & $* * * \uparrow$ \\
\hline$M C P-1$ & $\begin{array}{l}\text { vs Renal } \\
\text { adipocyte CM }\end{array}$ & $* * * \uparrow$ & $* * * \uparrow$ & n.s. & $* \uparrow$ & $\mathrm{p}=1$ & $* * * \downarrow$ \\
\hline$V E G F$ & $\begin{array}{l}\text { vs Renal } \\
\text { adipocyte CM }\end{array}$ & $* * \downarrow$ & $* * * \uparrow$ & n.s. & $* * * \uparrow$ & $\mathrm{p}=1$ & n.s. \\
\hline Adiponectin & $\begin{array}{l}\text { vs Renal } \\
\text { adipocyte CM }\end{array}$ & $* * * \downarrow$ & $* * * \downarrow$ & n.a. & $* * \downarrow$ & $\mathrm{p}=1$ & n.a. \\
\hline$I L-6$ & $\begin{array}{l}\text { vs } \\
\text { Subcutaneous } \\
\text { adipocyte CM }\end{array}$ & n.s. & $* * * \uparrow$ & n.s. & $* * * \uparrow$ & n.s. & $\mathrm{p}=1$ \\
\hline$I L-8$ & $\begin{array}{l}\text { vs } \\
\text { Subcutaneous } \\
\text { adipocyte CM }\end{array}$ & n.s. & $* * * \uparrow$ & n.s. & n.s. & $* * * \downarrow$ & $\mathrm{p}=1$ \\
\hline$M C P-1$ & $\begin{array}{l}\text { vs } \\
\text { Subcutaneous } \\
\text { adipocyte CM }\end{array}$ & $* * * \uparrow$ & $* * * \uparrow$ & n.s. & $* * \uparrow$ & $* * * \uparrow$ & $\mathrm{p}=1$ \\
\hline$V E G F$ & $\begin{array}{l}\text { vs } \\
\text { Subcutaneous } \\
\text { adipocyte CM }\end{array}$ & $* * * \downarrow$ & $* * * \uparrow$ & n.s. & $* * * \uparrow$ & n.s. & $\mathrm{p}=1$ \\
\hline
\end{tabular}

Values were considered to be significantly different at $p<0.05$. $* * * p<0.001, * * p<0.01, * p<0.05$, n.s. - not significant, n.a. - not analyzed. 
Finally, production of VEGF in renal adipocyteCM was statistically not significant compared to the control. IL-6 production from epicardial adipocytes was higher than that in all other cell lines $(p<0.001)$. Similar to IL-6, the production of IL-8 also differed among the mature adipocyte-CM depending on the origin of the adipocytes. VEGF production in epicardial preadipocytes was significantly reduced compared to other cell lines $(p<0.01)$, but it was significantly increased in the CM of fully differentiated epicardial adipocytes. In contrast, high VEGF content in CM of renal preadipocytes showed a significant decrease compared with that in $\mathrm{CM}$ from fully differentiated renal adipocytes $(\mathrm{p}<0.001)$. Adiponectin production from renal adipocytes was higher in comparison to all other cell lines $(p<0.001)$. Taken together, we found that adipokine production depends on the adipocyte maturation status and that it is cell origindependent.

Effect of co-culture of adipocytes and aortic smooth muscle cells on muscle cell proliferation

In order to obtain information about the effects of factors secreted by pre-adipocytes on the proliferation of smooth muscle cells, we measured the real time proliferation rate of HAoSMCs that were co-cultured with conditioned media from both renal and epicardial, and undifferentiated and mature adipocytes. Repeated measurements showed that only the epicardial adipocyteconditioned medium increased the proliferation rate of HAoSMCs compared to a HAoSMC control without treatment $(\mathrm{p}<0.05)$. We found no stimulatory effect of conditioned media from either renal or epicardial undifferentiated adipocytes, or from renal mature adipocytes on the proliferation of HAoSMCs.

\section{Discussion}

The aim of our study was to determine the effects of bioactive substances produced by epicardial and renal preadipocytes and adipocyte primary cell lines on the proliferation rate of HAoSMCs. Our results showed varying levels of adipokine production (IL-6, IL-8, MCP-1, VEGF and adiponectin) in conditioned media, which depended on cell origin and maturation status. The results also showed that the conditioned medium from differentiated (but not premature) epicardial adipocytes stimulated HAoSMC proliferation. Co-cultivation of HAoSMC with both premature and mature renal adipocytes had no influence on the growth of HAoSMCs.

Obesity is associated with an increased risk for the development of atherosclerosis and its clinical complications, and adipokines are thought to act as a molecular link in this relationship (Calle et al. 1999, Mathieu et al. 2010). Perivascular fat is an important endocrine and paracrine organ that produces various adipokines and many other substances (Mazurek et al. 2003, Yudkin et al. 2005, Miao and Li 2012). Due to the absence of an anatomic barrier, the active substances secreted by adipocytes readily gain access to the blood vessel wall (Barandier et al. 2005, Rajsheker et al. 2010). The local secretion of adipokines by perivascular adipose tissue via this mechanism may provide a direct link between obesity and vascular complications (Iacobellis $e t$ al. 2003, 2008). In addition to endothelial cells, VSMCs represent one of the most abundant cell types of the vascular wall. The bioactive substances secreted by adipocytes could lead to smooth muscle cell dysfunction and perhaps contribute to the development of proliferative vascular disease.

Our previous results showed that under basal conditions, i.e. in the absence of signs of atherosclerosis, not only are the adipose tissue-infiltrating cells important, but the adipocytes themselves are an important source of proinflammatory mediators; indeed, their phenotype is affected by the degree of adipocyte differentiation (Zdychova et al. 2012). Our measurements of the adipokine content in adipocyte conditioned media showed trends which are generally in accordance with previous findings. Our results suggest that epicardial adipocytes substantially differ from visceral (renal) adipocytes and that the former exhibit a proinflammatory phenotype even under basal conditions. Moreover, we reported an increased proliferation rate of HAoSMCs during co-culture with epicardial adipocyte-conditioned medium. It was previously shown (Lamers et al. 2011) that the conditioned medium from human adipocytes that were differentiated in vitro induces the proliferation of VSMCs in the human coronary artery. The same study also postulated that the proliferation-stimulating effect of conditioned media negatively correlated with the levels of adiponectin, but the authors found no correlation with IL-6 content. Further studies by the same group found a strong correlation among conditioned medium, VEGF content and the VSMC proliferation rate. VEGF seems to contribute to VSMC proliferation via an autocrine/paracrine mechanism. Treatment of VSMCs with the VEGF-containing conditioned medium induced 
VEGF secretion in the VSMCs, increased the expression of vascular endothelial growth factor receptors 1 and 2, and stimulated the proliferation of VSMCs in a VEGFdependent manner (Schlich et al. 2013). Although our results partially agreed with Schlich's findings, we were unable to confirm the prominent role of VEGF as the mediator of adipocyte paracrine action. Our results demonstrated that only the conditioned medium from mature epicardial adipocytes was able to stimulate the proliferation of HAoSMCs. Conditioned media from epicardial and renal preadipocytes and from renal adipocytes had no effect on the growth of HAoSMCs compared with the control. In contrast, the VEGF content was increased in both the epicardial adipocyte- and in the renal preadipocyte-conditioned medium, but the renal preadipocyte-conditioned medium exhibited only a very slight stimulatory effect on HAoSMC proliferation. We may speculate about several possible explanations for this phenomenon. First, we used conditioned media obtained from primary adipocyte cell lines that were derived exclusively from donors with no signs of diabetes and atherosclerosis. The study by Schlich et al. (2013) compared adipose tissue origin-dependent VEGF release and its correlation with the proliferation of VSMCs. Their results showed low VEGF release from the visceral and subcutaneous fat of lean subjects, together with no effect on the proliferation rate of VSMCs. The presence of obesity, especially the combination of obesity and diabetes, seems to markedly increase the levels of VEGF, together with the VSMC proliferation rate, in the case of visceral fat tissue. We can only speculate on the effect of the epicardial fat tissue-conditioned medium from lean subjects on the VSMC proliferation rate when obesity and diabetes are not present. It should be noted from Schlich's study that complex conditioned media obtained by incubation with adipose tissue biopsies were used. Second, the discrepancy between the results of the HAoSMC proliferation rate could be, at least in part, related to the adiponectin produced by renal adipocytes. The adiponectin content in the conditioned medium of renal adipocyte cell lines was higher compared to all other conditioned media. The study by Lamers et al. (2011) showed that adiponectin content negatively correlates with the proliferation of VSMCs. The third possibility is that because the secretory profile of human adipocytes is complex, it is probable that the interactions of many adipokines affect the final result. A recent study published by Ruan et al. (2010) featured liquid chromatography-tandem mass spectrometry technology to analyze the secretome of PVAT. Their proteomic analysis identified 81 proteins from PVAT, including 21 proteins that were previously identified in several types of adipocytes and 60 proteins that were identified for the first time by Ruan's group. The effect of the individual components could be studied through the use of specific inhibitors. Therefore, further studies could highlight the detailed impact of perivascular fat, alone and together with visceral fat-derived adipokines, on the proliferation of VSMCs.

A limitation of the present study is that EAT samples and samples of subcutaneous and renal fat tissue cannot be sampled simultaneously during a surgical procedure in the same donor. Unfortunately, these types of multiple biopsies are not possible at our institute for technical and ethical reasons. We attempted to overcome this obstacle by matching donors. Another point that should be discussed is the fact that EAT from healthy human donors is essentially unobtainable, and therefore, we cannot exclude the possibility that the inflammatory state in the donor's EAT was affected by the underlying pathology (cardiomyopathy). Nevertheless, previous studies (Mazurek et al. 2003, Hug and Lodish 2005, Sacks and Fain 2007) have shown that the most prominent cause of the proinflammatory phenotype of EAT is the presence of coronary artery disease. To avoid this problem, we obtained fat samples exclusively from donors with no clinical signs of atherosclerosis.

On the one hand, we found no effects on the proliferation rate of HAoSMCs of conditioned medium produced by renal preadipocyte and adipocyte cell lines. On the other hand, bioactive substances produced by epicardial adipocytes demonstrated a potential stimulatory effect on the HAoSMC proliferation rate under basal conditions, i.e. in the absence of clinical signs of atherosclerosis, which could locally contribute to the development of proliferative vascular disease.

\section{Conflict of Interest}

There is no conflict of interest.

\section{Acknowledgements}

This study was supported by grant no. NT 13188-4 from IGA MHCR. 


\section{References}

BARANDIER C, MONTANI J-P, YANG Z: Mature adipocytes and perivascular adipose tissue stimulate vascular smooth muscle cell proliferation: effects of aging and obesity. Am J Physiol Heart Circ Physiol 289: $1807-$ $1813,2005$.

CALDER PC, AHLUWALIA N, BUETLER T, CLEMENT K, CUNNINGHAM K, ESPOSITO K, JÖNSSON LS, KOLB H, LANSINKM, MACROS A, MARGIORIS A, MATUSHESKI N, NORDMANN H, O’BRIEN J, PUGLIESE G, RIZKALLA S, SCHLKWIIJK C, TUOMILEHTO J, WÄRNBERG J, WATZL B, WINKLHOFER-ROOB BM: Dietary factors and low-grade inflammation in relation to overweight and obesity. Br J Nutr 106: S5-S78, 2011.

CALle EE, THUN MJ, PETRELli JM, RODRIGUEZ C, HEATH CW: Body-mass index and mortality in a prospective cohort of U.S. adults. N Engl J Med 341: 1097-1105, 1999.

CHATTERJEE TK, STOLL LL, DENNING GM, HARRELSON A, BLOMKALNS AL, IDELMAN G, ROTHENBERG FG, NELTNER B, ROMIG-MARTIN SA, DICKSON EW, RUDICH S, WEINTRAUB NL: Proinflammatory phenotype of perivascular adipocytes: influence of high-fat feeding. Circ Res 104: 541-549, 2009.

CINTI S: Adipocyte differentiation and transdifferentiation: plasticity of the adipose organ. $J$ Endocrinol Invest 25 : 823-835, 2002.

DAVIS-DUSENBERY BN, WU C, HATA A: Micromanaging vascular smooth muscle cell differentiation and phenotypic modulation. Arterioscler Thromb Vasc Biol 31: 2370-2377, 2011.

DESPRÉS J-P, LEMIEUX I, BERGERON J, PIBAROT P, MATHIEU P, LAROSE E, RODÉS-CABAU J, BERTRAND OF, POIRIER P: Abdominal obesity and the metabolic syndrome: contribution to global cardiometabolic risk. Arterioscler Thromb Vasc Biol 28: 1039-1049, 2008.

DIETZE-SCHROEDER D, SELL U, UHLIG M, KOENEN M, ECKEL J: Autocrine action of adiponectin on human fat cells prevents the release of insulin resistance-inducing factors. Diabetes 54: 2003-2011, 2005.

DING J, KRITCHEVSKY SB, HARRIS TB, BURKE GL, DETRANO RC, SZKLO M, JEFFREY CARR J: The association of pericardial fat with calcified coronary plaque. Obesity (Silver Spring) 16: 1914-1919, 2008.

FRIED SK, MOUSTAID-MOUSSA N: Culture of adipose tissue and isolated adipocytes. Methods Mol Biol 155: 197-212, 2001.

GAO Y-J: Dual modulation of vascular function by perivascular adipose tissue and its potential correlation with adiposity/lipoatrophy-related vascular dysfunction. Curr Pharm Des 13: 2185-2192, 2007.

GUSTAFSON B: Adipose tissue, inflammation and atherosclerosis. J Atheroscler Thromb 17: 332-341, 2010.

HUG C, LODISH HF: The role of the adipocyte hormone adiponectin in cardiovascular disease. Curr Opin Pharmacol 5: 129-134, 2005.

IACOBELliS G, RIBAUDO MC, ASSAEL F, VECCI E, TIBERTI C, ZAPPATERRENO A, Di MARIO U, LEONETTI F: Echocardiographic epicardial adipose tissue is related to anthropometric and clinical parameters of metabolic syndrome: a new indicator of cardiovascular risk. J Clin Endocrinol Metab 88: 5163-5168, 2003.

IACOBELLIS G, GAO Y-J, SHARMA AM: Do cardiac and perivascular adipose tissue play a role in atherosclerosis? Curr Diab Rep 8: 20-24, 2008.

IKEDA U, IKEDA M, OOHARA T, OGUCHI A, KAMITANI T, TSURUYA Y, KANO S: Interleukin 6 stimulates growth of vascular smooth muscle cells in a PDGF-dependent manner. Am J Physiol 260: H1713-H1717, 1991.

KIEFER FW, COHEN P, PLUTZKY J: Fifty shades of brown: perivascular fat, thermogenesis, and atherosclerosis. Circulation 126: 1012-1015, 2012.

LAMERS D, SCHLICH R, GREULICH S, SASSON S, SELL H, ECKEL J: Oleic acid and adipokines synergize in inducing proliferation and inflammatory signalling in human vascular smooth muscle cells. J Cell Mol Med $\mathbf{1 5}$ : 1177-1188, 2011.

MATHIEU P, LEMIEUX I, DESPRÉS J-P: Obesity, inflammation, and cardiovascular risk. Clin Pharmacol Ther 87: 407-416, 2010. 
MAZUREK T, ZHANG L, ZALEWSKI A, MANNION JD, DIEHL JT, ARAFAT H, SAROV-BLAT L, O'BRIEN S, KEIPER EA, JOHNSON AG, MARTIN J, GOLDSTEIN BJ, SHI Y: Human epicardial adipose tissue is a source of inflammatory mediators. Circulation 108: 2460-2466, 2003.

MIAO C-Y, LI Z-Y: The role of perivascular adipose tissue in vascular smooth muscle cell growth. Br J Pharmacol 165: 643-658, 2012.

OWENS GK, KUMAR MS, WAMHOFF BR: Molecular regulation of vascular smooth muscle cell differentiation in development and disease. Physiol Rev 84: 767-801, 2004.

PICHÉ M-E, LAPOINTE A, WEISNAGEL SJ, CORNEAU L, NADEAU A, BERGERON J, LEMIEUX S: Regional body fat distribution and metabolic profile in postmenopausal women. Metabolism 57: 1101-1107, 2008.

RAJSHEKER S, MANKA D, BLOMKALNS AL, CHATTERJEE TK, STOLL LL, WEINTRAUB NL: Crosstalk between perivascular adipose tissue and blood vessels. Curr Opin Pharmacol 10: 191-196, 2010.

RUAN CC, ZHU DL, CHEN QZ, CHEN J, GUO SJ, LI XD, GAO PJ: Perivascular adipose tissue-derived complement 3 is required for adventitial fibroblast functions and adventitial remodeling in deoxycorticosterone acetate-salt hypertensive rats. Arterioscler Thromb Vasc Biol 30: 2568-2574, 2010.

SACKS HS, FAIN JN: Human epicardial adipose tissue: a review. Am Heart J 153: 907-917, 2007.

SCHLICH R, WILLEMS M, GREULICH S, RUPPE F, KNOEFEL WT, OUWENS DM, MAXHERA B, LICHTENBERG A, ECKEL J, SELL H: VEGF in the crosstalk between human adipocytes and smooth muscle cells: depot-specific release from visceral and perivascular adipose tissue. Mediators Inflamm 2013: Article ID982458, 2013.

SCHULTZ K, MURTHY V, TATRO JB, BEASLEY D: Endogenous interleukin-1 alpha promotes a proliferative and proinflammatory phenotype in human vascular smooth muscle cells. Am J Physiol Heart Circ Physiol 292: H2927-H2934, 2007.

SZASZ T, BOMFIM GF, WEBB RC: The influence of perivascular adipose tissue on vascular homeostasis. Vasc Health Risk Manag 9: 105-116, 2013.

TAGUCHI R, TAKASU J, ITANI Y, YAMAMOTO R, YOKOYAMA K, WATANABE S, MASUDA Y: Pericardial fat accumulation in men as a risk factor for coronary artery disease. Atherosclerosis 157: 203-209, 2001.

YUDKIN JS, ERINGA E, STEHOUWER CDA: "Vasocrine" signalling from perivascular fat: a mechanism linking insulin resistance to vascular disease. Lancet 365: 1817-1820, 2005.

YUE TL, WANG X, SUNG CP, OLSON B, MCKENNA PJ, GU JL, FEUERSTEIN GZ: Interleukin-8. A mitogen and chemoattractant for vascular smooth muscle cells. Cardiovasc Res 75: 1-7, 1994.

ZDYCHOVA J, KRALOVA LESNA I, MALUSKOVA J, JANOUSEK L, CAHOVA M, KAZDOVA L: Comparison of gene expression of epicardial and visceral adipocytes with regard to the differentiation stage. Neuro Endocrinol Lett 33 (Suppl 2): 93-97, 2012.

ZHOU Y, WEI Y, WANG L, WANG X, DU X, SUN Z, DONG N, CHEN X: Decreased adiponectin and increased inflammation expression in epicardial adipose tissue in coronary artery disease. Cardiovasc Diabetol 10: 2, 2011. 